\title{
Mutations in GLUT2, the gene for the liver-type glucose transporter, in patients with Fanconi-Bickel syndrome
}

René Santer, Reinhard Schneppenheim, Anja Dombrowski, Hermann Götze, Beat Steinmann \& Jürgen Schaub

Nature Genet. 17, 324-326 (1997).

Due to an error, the designation of the GLUT2 mutation of patient 0301 is wrong. C1251T has to be replaced by C1213T. As the amino-acid code (R301X) was correctly stated, this does not affect the discussion of the results and the conclusions of the paper. We regret this error.

\section{Atm selectively regulates distinct p53-dependent cell-cycle checkpoint and apoptotic pathways}

Carrolee Barlow, Kevin D. Brown , Chu-Xia Deng, Danilo A. Tagle \& Anthony Wynshaw-Boris

Nature Genet. 17, 453-456 (1997).

We inadvertantly failed to acknowledge Stacie Anderson for her assistance and advice in performing the flow cytometry experiments. We regret this omission.

\section{corrections}

\section{Genomic DNA transfer with a high-capacity adenovirus vector results in improved in vivo gene expression and decreased toxicity}

Gudrun Schiedner, Núria Morral, Robin J. Parks, Ying Wu, Suzanne C. Koopmans, Claire Langston, Frank L. Graham, Arthur L. Beaudet \& Stefan Kochanek

Nature Genet. 18, 180-183 (1998).

The corresponding author's e-mail address was printed incorrectly. Dr. Stefan Kochanek's e-mail address is stefan.kochanek@medizin.uni-koeln.de. We regret this error.

\section{Localisation of a gene implicated in a severe speech and language disorder}

Simon Fischer, Faraneh Vargha-Khadem, Kate E. Watkins, Anthony P. Monaco \& Marcus E. Pembry Nature Genet. 18, 168-170 (1998).

Due to a printing error, the text on Table 1, printed here in full, was obscured. We regret this error.

\begin{tabular}{|c|c|c|c|c|c|c|c|}
\hline \multirow[b]{2}{*}{ Locus } & \multicolumn{7}{|c|}{ Recombination fractions $(\theta)$} \\
\hline & Dist (cM) & 0.00 & 0.05 & 0.10 & 0.20 & $\theta_{\max }$ & $Z_{\max }$ \\
\hline $\begin{array}{l}\text { D7S527* } \\
\text { D7S518 } \\
\text { D7S2453 } \\
\text { D 7S501 } \\
\text { D7S2420 } \\
\text { D7S496 } \\
\text { D } 52459\end{array}$ & $\begin{array}{l}3.9 \\
3.8 \\
3.1 \\
0.9 \\
0.0 \\
0.0 \\
0.8\end{array}$ & $\begin{array}{l}-\infty \\
-\infty \\
-\infty \\
-\infty \\
-\infty \\
-\infty \\
-\infty\end{array}$ & $\begin{array}{l}1.16 \\
2.74 \\
1.27 \\
4.55 \\
4.41 \\
3.34 \\
4.83\end{array}$ & $\begin{array}{l}1.69 \\
2.94 \\
1.46 \\
4.36 \\
4.19 \\
3.44 \\
4.62\end{array}$ & $\begin{array}{l}1.77 \\
2.67 \\
1.19 \\
3.59 \\
3.37 \\
2.97 \\
3.79\end{array}$ & $\begin{array}{l}0.158 \\
0.105 \\
0.103 \\
0.045 \\
0.043 \\
0.087 \\
0.043\end{array}$ & $\begin{array}{l}1.82 \\
2.94 \\
1.46 \\
4.55 \\
4.41 \\
3.45 \\
4.84\end{array}$ \\
\hline $\begin{array}{l}\text { D7S2425 } \\
D 75692 \\
075687 \\
D 752418 \\
D 75523 \\
D 752554 \\
D 75522 \\
D 752460 \\
D 75633 \\
D 7 S 486^{*} \\
C^{*}\end{array}$ & $\begin{array}{l}0.0 \\
1.9 \\
0.0 \\
0.5 \\
0.0 \\
1.2 \\
0.0 \\
0.1 \\
0.1 \\
0.0 \\
1.0\end{array}$ & $\begin{array}{l}5.67 \\
6.62 \\
6.02 \\
5.72 \\
6.62 \\
5.72 \\
5.41 \\
5.79 \\
4.53 \\
6.22 \\
5.46\end{array}$ & $\begin{array}{l}5.25 \\
6.11 \\
5.55 \\
5.30 \\
6.11 \\
5.27 \\
5.01 \\
5.33 \\
4.17 \\
5.71 \\
5.05\end{array}$ & $\begin{array}{l}4.81 \\
5.57 \\
5.06 \\
4.85 \\
5.57 \\
4.80 \\
4.58 \\
4.85 \\
3.79 \\
5.17 \\
4.63\end{array}$ & $\begin{array}{l}3.84 \\
4.40 \\
3.99 \\
3.88 \\
4.40 \\
3.78 \\
3.66 \\
3.80 \\
2.97 \\
4.00 \\
3.70\end{array}$ & $\begin{array}{l}0.000 \\
0.000 \\
0.000 \\
0.000 \\
0.000 \\
0.000 \\
0.000 \\
0.000 \\
0.000 \\
0.000 \\
0.000\end{array}$ & $\begin{array}{l}5.67 \\
6.62 \\
6.02 \\
5.72 \\
6.62 \\
5.72 \\
5.41 \\
5.79 \\
4.53 \\
6.22 \\
5.46\end{array}$ \\
\hline $\begin{array}{l}D 7 S 643 \\
D 7 S 480 \\
D 7 S 2486 \\
D 7 S 487 \\
D 7 S 504 \\
D 75530 *\end{array}$ & $\begin{array}{l}0.9 \\
2.2 \\
0.6 \\
2.6 \\
3.8\end{array}$ & $\begin{array}{l}-\infty \\
-\infty \\
-\infty \\
3.58 \\
-\infty \\
-\infty\end{array}$ & $\begin{array}{l}4.83 \\
4.62 \\
4.55 \\
3.25 \\
3.45 \\
2.27\end{array}$ & $\begin{array}{l}4.62 \\
4.41 \\
4.36 \\
2.90 \\
3.34 \\
2.71 \\
\end{array}$ & $\begin{array}{l}3.79 \\
3.61 \\
3.59 \\
2.15 \\
2.75 \\
2.59\end{array}$ & $\begin{array}{l}0.043 \\
0.044 \\
0.045 \\
0.000 \\
0.054 \\
0.131\end{array}$ & $\begin{array}{l}4.83 \\
4.63 \\
4.55 \\
3.58 \\
3.45 \\
2.76 \\
\end{array}$ \\
\hline
\end{tabular}

Markers are listed in the order proximal-distal. Distances between neighbouring markers are from the latest Généthon linkage map ${ }^{13}$. Markers indicated with an asterisk were part of the HGMP set ${ }^{12}$ used in the genome-wide linkage search; the remaining markers were used for fine mapping of the implicated region. Shading indicates the 3.8-5.6 cM region that co-segregates perfectly with the disorder. 